\title{
EFFICIENT PERFORMANCE INDICES FOR VOLTAGE COLLAPSE DETECTION
}

\author{
A. A. Abou El-Ela ${ }^{1}$ A. M. Kinawy ${ }^{1}$ R. A. El-Sehiemy ${ }^{2}$ M. T. Mouwafi ${ }^{1}$ \\ 1) Electrical Engineering Department, Faculty of Engineering, Shebin El-Kom, \\ Minoufiya University, Egypt \\ 2) Electrical Engineering Department, Faculty of Engineering, \\ Kafrelsehiekh University, Egypt
}

\begin{abstract}
This paper proposes six performance indices (PIs) for efficient detecting the most weakness load buses which may be subjected to voltage collapse occurrence at normal and emergency conditions. The classification of the suggested ranking PIs are dependent on their severity on the voltage collapse. The suggested PIs are based on the following physical quantities: equivalent system impedance and the related load impedance at each load bus, equivalent system admittance and the related load admittance at each load bus, load bus voltages and loading levels at different loading buses.

These PIs derived based on circuit's theory and tested using one standard system, namely IEEE 14bus. In addition, the capability of these PIs is demonstrated using the west Delta network (WDN) as a real part of the Unified Egyptian Network (UEN). The results detect efficiently the most sever load buses which may be subjected to voltage collapse occurrence.

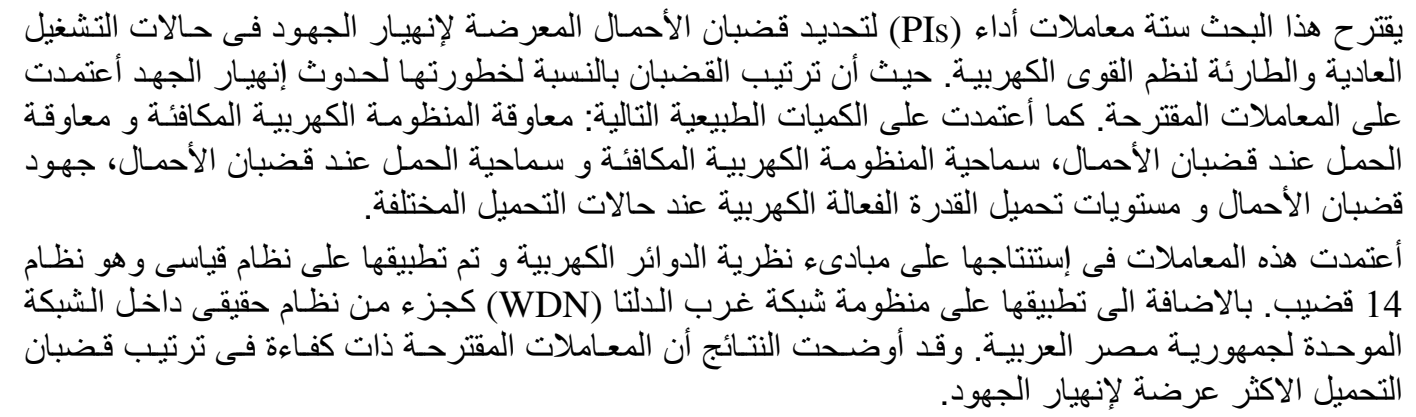

Keywords: Performance indices, Voltage collapse, Sensitive, Insensitive, Load bus, Risk, Ranking

\section{INTRODUCTION}

Nowadays, the power systems become more complicated and having many buses and transmission lines after interconnecting the power systems to become interconnected networks in several areas in the world. The operation of power systems closer to their load limits is dictated by the needs of deregulated electricity markets. However, as a result, several blackouts have occurred due to voltage instability. This means that voltage stability has become a matter of serious concern for system operators and is the subject of considerable investigation because of its importance in terms of the security of the system and the quality of the power. Significant efforts are still being directed towards definitions, classifications, new concepts, practices and tools for solving the voltage-stability and security-analysis problems [1].

Voltage collapse is a major concern in modern power systems, which are steadily approaching the operating limits imposed by economic and environmental constraints. The expansion of the conventional power system allows for incidences where unexpected contingencies to go unconsidered, particularly due to the deregulation process in power systems. It is, therefore, difficult to predefine all the outages and complexities and control counterparts. Stability, security and efficiency are of utmost importance in planning and operating the power systems.

Many performance indices for categorizing voltage stability in static security stability assessment in power systems have been developed over the years. Most of them are defined by the current operating point to different stability boundaries or collapse point and are typically based on sensitivity techniques and multiple load flow results. Techniques such as the Voltage Collapse Proximity Indicator (VCPI), Voltage Instability Predictor Index (VIPI) and energy method, L-Indicator which was 
derived from load flow and continuation power flow, and an Integrated Logarithmic Index (ILI) are some typical methods for assessing static voltage instability problems. So that, it is very important to detect the voltage stability through making a suitable rank procedure to identify the state of load buses and/or critical lines according to their severity risk. Hence, the critical buses and/or critical lines are defined.

Musirin and Abdul Rahman [2] demonstrated the use of line stability index termed as fast voltage stability index (FVSI) in order to determine the maximum loadability in a power system. The bus that is ranked highest is identified as the weakest bus since it can withstand a small amount of load before causing voltage collapse. Nithiyananthan et al. [3] proposed a methodology for line outage ranking based on Reactive Compensation Index (RCI) using artificial shunt compensators to maintain the load bus voltages to its pre-outage values. Sutha and Kamaraj [4] used Wavelet Transform Based Artificial Neural Networks (WNN) to estimate the Real Power Index (RPI) of all the critical contingencies under any loading conditions. Silveira et al. [5] proposed Sensitivity indices based on the ratio of the differential change in a variable to the differential change in the other variable. Zhu et al. [6] presented PIs for evaluating the impact of VAr optimization with coordinated static VAr compensator (SVC) model no loss minimization and voltage improvement.

\section{PROPOSED PERFORMANCE INDICES}

A six performance indices are proposed in this paper to rank the load buses according to their severity as follows:

\subsection{Two PIs Based on System Impedance}

Based on Thevenin's theorem that provides an extremely valuable means for reducing a complex circuit to a simple circuit containing an ideal voltage source in series with equivalent impedance, thus, the complex power circuit shown in Fig. 1(a) can always be reduced to the Thevenin's equivalent as shown in Fig. 1(b).

From this circuit, the real power transmitted to load can be calculated, as:

$$
\begin{aligned}
P_{L} & =\operatorname{real}\left\{V_{i} I_{i}^{*}\right\} \\
& =\operatorname{real}\left\{\frac{Z_{i} E_{T H}}{Z_{i}+Z_{i i}} \times \frac{E_{T H}^{*}}{\left[Z_{i}+Z_{i i}\right]^{*}}\right\}
\end{aligned}
$$

or,

$$
P_{L}=\operatorname{real}\left\{\frac{Z_{i}}{\left[Z_{i}+Z_{i i}\right]^{2}} E_{T H}^{2}\right\}
$$

To obtain the maximum power transmitted $\left(\mathrm{P}_{\mathrm{L}}{ }^{\mathrm{max}}\right)$ to the load, $\partial P_{L} / \partial Z_{i}$ is calculated and equals to zero as follows:

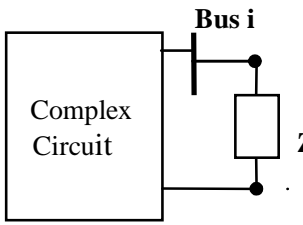

(a) Original circuit

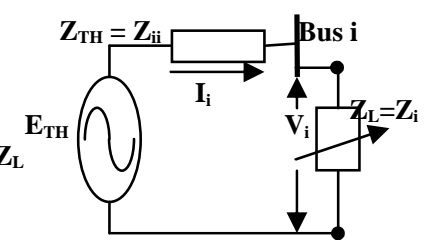

(b) Thevenin equivalent circuit
Fig. 1 Reduction network using Thevenin's theorem

$$
\begin{aligned}
& \frac{\partial P_{L}}{\partial Z_{i}}=0 \\
& \operatorname{real}\left\{\frac{\left[Z_{i}+Z_{i i}\right]^{2} E_{T H}^{2}-2 \times Z_{i} E_{T H}^{2}\left[Z_{i}+Z_{i i}\right]}{\left[Z_{i}+Z_{i i}\right]^{4}}\right\}=0
\end{aligned}
$$

Hence, the maximum power transmitted to the load occurs at $\mathrm{Z}_{\mathrm{i}}=\mathrm{Z}_{\mathrm{ii}}$ can be calculated, as:

$$
P_{L}^{\max }=\operatorname{real}\left\{\frac{E_{T H}^{2}}{4\left|Z_{i i}\right|}\right\}
$$

For preventing the occurrence of the voltage collapse in power systems, it should satisfy the following inequality:

$$
\left|Z_{i i} / Z_{i}\right| \leq 1.0 ; i=1, \ldots . N
$$

Where,

$Z_{i i}$ is the ith diagonal elements of the Thevenin's equivalent impedance matrix.

$N$ is the number of load buses.

$Z_{i}$ is the load impedance, which is calculated, as:

$$
Z_{i}=\left|V_{L i}\right|^{2} / S_{i}^{*}
$$

Where,

$\left|V_{L i}\right|$ is the magnitude of the load voltage under normal and emergency conditions at bus $i$.

$S_{i}{ }^{*}$ is the conjugate of the apparent power at bus $i$.

However, the active and reactive powers of the loads and generators are represented by shunt elements with appropriate signs. Now, referring to equation (3), a first performance voltage collapse index (PI) based on system impedance is introduced to rank the load-bus voltages according to their severity risk situation for normal and emergency conditions as:

$$
\left(P I_{1 Z}\right)_{i}=\left(\left|Z_{i i}\right|-\left|Z_{i}\right|\right) /\left|Z_{i}\right|, i=1, \ldots \ldots . N
$$


The values of $\left|\mathrm{Z}_{\mathrm{ii}}\right|$ and $\left|\mathrm{Z}_{\mathrm{i}}\right|$ indicate the largest and the smallest PI. Hence, the buses that have the largest negative values of PI are considered as insensitive to the voltage collapse, and these buses will be indexed at the bottom of PI list. While, the buses that have the smallest negative values of PI will be indexed at the top of this list. These buses are considered as the most sensitive buses to the voltage collapse.

Figure 2 shows the PV nominal curve at bus $i$. In this figure, the maximum loading point (MLP) occurs at $Z_{i}=Z_{i i}$, and the nominal loading margin is the distance between the base case loading and the loading at the nose of the curve. In other words, the best loading condition is occurred $Z_{i} \geq Z_{i i}$. So, for preventing the occurrence of the voltage collapse in power system, it should satisfy the following inequality:

$$
\left|P_{L i} / P_{L i}^{\max }\right| \leq 1.0 ; i=1, \ldots . N
$$

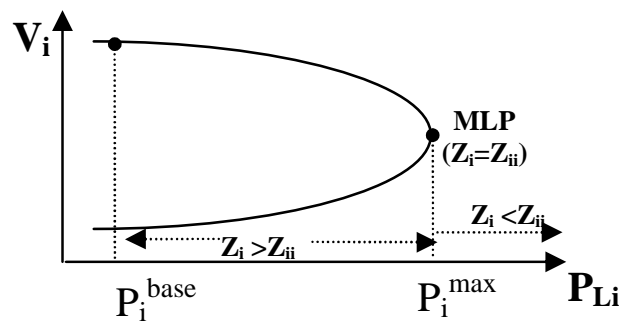

Fig. 2 PV nominal curve at bus $i$

By substituting from Equations (1) and (2) into (6), the second performance voltage collapse index (PI) is obtained based on system impedance to rank the load-bus voltages according to their severity risk situation for normal and emergency conditions, as:

$$
\left(P I_{2 Z}\right)_{i}=\frac{4\left|Z_{i}\right|\left|Z_{i i}\right|}{\left|Z_{i}+Z_{i i}\right|^{2}} \leq 1, i=1, \ldots \ldots . . N
$$

From equation (7), the buses that have the smallest positive values of PI are considered as insensitive to voltage collapse, and these buses will be indexed at the bottom of a list. While, the buses that have the largest positive values of PI will be indexed at the top of this list. These buses are considered as the most sensitive buses to the voltage collapse

\subsection{Two PIs Based on System Admittance}

Based on Norton's theorem, that provides an extremely valuable means for reducing a complex circuit to a simple circuit containing an ideal current source in parallel with equivalent impedance. Thus, the complex power circuit in Fig. 3(a) can be reduced to the Norton's equivalent in Fig. 3(b).

From this circuit, the real power transmitted to the load can be calculated as:

$$
\begin{aligned}
& P_{L}=\operatorname{real}\left\{V_{i} I_{i}^{*}\right\} \\
= & \operatorname{real}\left\{\frac{I_{N}}{Y_{i i} Y_{i}\left[1 / Y_{i}+1 / Y_{i i}\right]} \times \frac{I_{N}^{*}}{Y_{i i}^{*}\left[1 / Y_{i}+1 / Y_{i i}\right]^{*}}\right\} \\
= & \operatorname{real}\left\{\frac{I_{N}^{2}}{Y_{i} Y_{i i}^{2}\left[1 / Y_{i}+1 / Y_{i i}\right]^{2}}\right\}
\end{aligned}
$$

The maximum power transmitted to the load $\left(\mathrm{P}_{\mathrm{L}}{ }^{\max }\right)$ occurs at $\partial P_{L} / \partial Y_{i}=0$, that gives $Y_{i}=Y_{i i}$. So that,

$$
P_{L}^{\max }=\operatorname{real}\left\{\frac{I_{N}^{2}}{4\left|Y_{i i}\right|}\right\}
$$

Similarly, for preventing the occurrence of voltage collapse in power systems, it should satisfy the following inequality:

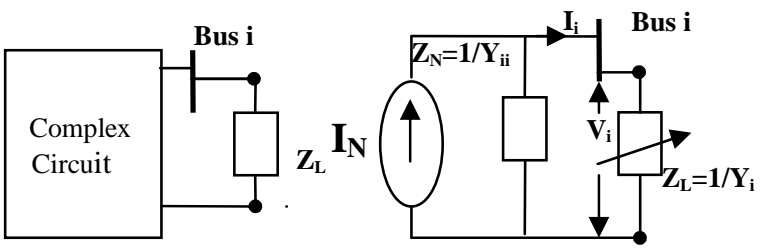

(a) Original circuit

(b) Norton equivalent circuit

Fig. 3 Reduction network using Norton's theorem

$$
\left|Y_{i i} / Y_{i}\right| \geq 1.0 ; i=1, \ldots . N
$$

Where,

$Y_{i i}$ is the the ith diagonal elements of the admittance matrix.

$Y_{i}$ is the load admittance and equals to the inverse of load impedance at bus $i$.

Now, referring to equation (10), the first performance voltage collapse index (PI) based on system admittance is introduced to rank the load-bus voltages according to their severity risk situation for normal and emergency conditions, as:

$$
\left(P I_{1 Y}\right)_{i}=\left(\left|Y_{i i}\right|-\left|Y_{i}\right|\right) /\left|Y_{i i}\right|, i=1, \ldots \ldots . N
$$

From equation (11), the buses that have the largest positive values of PI are considered as insensitive to voltage collapse, and these buses will be indexed at the bottom of a list. While, the buses that have the smallest positive values of PI will be indexed at the top of this list. These buses are considered as the most sensitive buses to voltage collapse.

Similarly, substatiting from equations (8) and (9) into (6), the second performance voltage collapse index (PI) based on system admittance to rank the 
load-bus voltages according to their severity risk situation for normal and emergency conditions can be expressed as:

$$
\left(P I_{2 Y}\right)_{i}=\frac{4}{Y_{i} Y_{i i}\left|1 / Y_{i}+1 / Y_{i i}\right|^{2}} \leq 1, i=1, \ldots \ldots N
$$

After computing PIs, the buses that have the smallest positive values of PIs are considered as insensitive to voltage collapse, and these buses will be indexed at the bottom of a list. While, the buses that have the largest positive values of PIs will be indexed at the top of this list. These buses are considered as the most sensitive buses to voltage collapse.

\subsection{Voltage Performance Index}

It measures the voltage deviation of each load bus, at normal and emergency conditions, with respect to specified voltage which equals to one p.u. So that, voltage performance index can be calculated from:

$$
\left(P I_{V}\right)_{i}=\left(\left|V_{s p}-V_{i}\right|\right) / V_{s p}, i=1, \ldots \ldots . N
$$

Where,

$V_{s p}$ is the specified voltage (equals to one per unit)

$V_{i}$ is the voltage magnitude at node $i$.

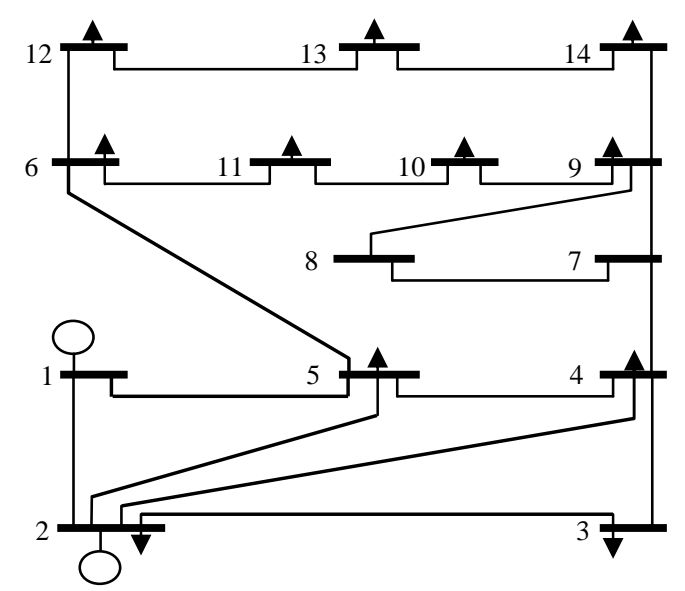

Fig. 4 Single line diagram for 14-bus test system

The load buses can be indexed according to equation (13). Where, the buses that have the largest positive values are indexed at the top of the list which is considered as the most sensitive buses to voltage collapse. While, the buses that have the smallest positive values are indexed at the bottom of this list which are considered as insensitive buses to voltage collapse.

\subsection{Loading Performance Index}

The performance index based on the active power is determined based on the load deviation at each load bus with respect to the total load of the system, as:

$$
\left(P I_{P}\right)_{i}=\left(P_{L t}-P_{L i}\right) / P_{L t}, i=1, \ldots \ldots . N
$$

Where,

$P_{L t}$ is the total active load powers at all nodes.

$P_{L i}$ is the load power at node $i$.

From equation (14), the buses that have the smallest positive values of PIs have heavily loaded are considered as sensitive to voltage collapse, and these buses will be indexed at the top of the list. While, the buses that have the largest positive values have light loaded, the PIs will be indexed at the bottom of this list. These buses are considered as insensitive buses to voltage collapse.

\section{APPLICATIONS}

\subsection{Test Systems}

The proposed performance indices are applied on IEEE standard 14-bus (Fig. 4) [7] and a real power system of the WDN system as a part of the Unified Egyptian Network (UEN) [8]. Bus 1 in all test systems is taken as slack bus. In addition, the load flow is done using MATPOWER toolbox in MatLab code program.

Different emergency conditions are assumed as:

- For the 14-bus test system. a - Lines 2-3 and 4-5 are outage. $\mathrm{b}-$ Load at bus 14 is increased with $50 \%$.

- For the west delta system. a-Lines 24-25, and 5-31 are outage. b-Load at bus 36 is increased with $50 \%$.

\subsection{Results and Comments}

\subsubsection{Normal conditions}

Tables 1 and 2 show the proposed PIs of load-buses according to their severity due to the voltage collapse based on the system impedance, admittance, voltage and loading for 14-bus test system. From these tables, it can be shown that, bus 3 is the most sensitive bus based on $\mathrm{PI}_{1 \mathrm{Z}}, \mathrm{PI}_{2 \mathrm{Z}} \mathrm{PI}_{1 \mathrm{Y}}, \mathrm{PI}_{2 \mathrm{Y}}$ and $\mathrm{PI}_{\mathrm{P}}$ which is heavily loaded with a minimum voltage deviation. So that, the impedance deviation of $\mathrm{Z}_{\mathrm{ii}}$ with respect to $Z_{i}$ is decreased (the admittance deviation of $Y_{i}$ with respect to $Y_{i i}$ is decreased). While, this bus is the most insensitive bus based on $\mathrm{PI}_{\mathrm{V}}$ because it has a minimum voltage deviation with respect to flat voltage. On the contrary, bus 5 is the most insensitive bus based on $\mathrm{PI}_{1 \mathrm{Z}}, \mathrm{PI}_{2 \mathrm{Z}} \mathrm{PI}_{1 \mathrm{Y}}$ and $\mathrm{PI}_{2 \mathrm{Y}}$ where the impedance deviation of $Z_{i i}$ with respect to $\mathrm{Z}_{\mathrm{i}}$ is increased (the admittance deviation of $\mathrm{Y}_{\mathrm{i}}$ with respect to $Y_{i i}$ is increased). In another side, bus 8 is the most sensitive bus based on $\mathrm{PI}_{\mathrm{V}}$ because it has a maximum voltage deviation. Based on $\mathrm{PI}_{\mathrm{P}}$, bus 11 is the most insensitive bus where it has lightly loaded. Moreover, Two PIs based on the system impedance give the same ordering. Also, the same ordering 
obtained using two PIs based on the system admittance.

Table 1 Ranking of load buses based on impedance and admittance matrices at normal condition for 14-bus system

\begin{tabular}{cccccccc}
\hline $\begin{array}{c}\mathrm{Ra} \\
\mathrm{nk}\end{array}$ & $\mathrm{PI}_{1 Z}$ & $\begin{array}{c}\mathrm{Ra} \\
\mathrm{nk}\end{array}$ & $\mathrm{PI}_{2 Z}$ & $\begin{array}{c}\mathrm{Ran} \\
\mathrm{k}\end{array}$ & $\mathrm{PI}_{1 Y}$ & $\begin{array}{c}\mathrm{Ra} \\
\mathrm{nk}\end{array}$ & $\mathrm{PI}_{2 Y}$ \\
\hline 3 & -0.854 & 3 & 0.445 & 3 & 0.910 & 3 & 0.302 \\
9 & -0.928 & 9 & 0.252 & 8 & 0.974 & 8 & 0.098 \\
8 & -0.941 & 8 & 0.211 & 14 & 0.975 & 14 & 0.094 \\
14 & -0.944 & 14 & 0.201 & 9 & 0.988 & 9 & 0.048 \\
4 & -0.954 & 4 & 0.170 & 4 & 0.988 & 4 & 0.045 \\
13 & -0.957 & 13 & 0.159 & 13 & 0.989 & 13 & 0.041 \\
10 & -0.972 & 10 & 0.105 & 2 & 0.990 & 2 & 0.039 \\
6 & -0.973 & 6 & 0.103 & 12 & 0.992 & 12 & 0.033 \\
12 & -0.977 & 12 & 0.087 & 10 & 0.994 & 10 & 0.024 \\
2 & -0.983 & 2 & 0.065 & 6 & 0.994 & 6 & 0.023 \\
11 & -0.989 & 11 & 0.045 & 11 & 0.996 & 11 & 0.015 \\
5 & -0.993 & 5 & 0.027 & 5 & 0.998 & 5 & 0.008 \\
\hline
\end{tabular}

Table 2 Ranking of load buses based on voltage and loading PIs at normal condition for 14-bus system

\begin{tabular}{cccc}
\hline Rank & PIV & Rank & PIP \\
\hline 8 & 0.090 & 3 & 0.6363 \\
6 & 0.070 & 4 & 0.8154 \\
11 & 0.057 & 9 & 0.8861 \\
9 & 0.056 & 2 & 0.9162 \\
12 & 0.055 & 14 & 0.9425 \\
10 & 0.051 & 13 & 0.9479 \\
13 & 0.051 & 6 & 0.9568 \\
2 & 0.045 & 10 & 0.9653 \\
14 & 0.036 & 5 & 0.9707 \\
5 & 0.020 & 12 & 0.9764 \\
4 & 0.019 & 11 & 0.9865 \\
3 & 0.010 & $1,7,8$ & --- \\
\hline "---" denotes that no load demand at this bus.
\end{tabular}

Figures 5 - 7 show the proposed PIs of loadbuses according to their severity due to the voltage collapse for WDN system. In figure 5 , it can be shown that, bus 33 is the most sensitive bus based on $\mathrm{PI}_{1 Z}$ and $\mathrm{PI}_{2 Z}$, which have the most heavily loaded. So, the impedance deviation of $\mathrm{Z}_{\mathrm{ii}}$ with respect to $\mathrm{Z}_{\mathrm{i}}$ is decreased. On the contrary, bus 52 is the most insensitive bus based on $\mathrm{PI}_{1 Z}$ and $\mathrm{PI}_{2 Z}$, because the impedance deviation of $Z_{i i}$ with respect to $Z_{i}$ is increased. In figure 6 , bus 33 is also the most sensitive bus based on $\mathrm{PI}_{1 \mathrm{Y}}$ and $\mathrm{PI}_{2 \mathrm{Y}}$, because the admittance deviation of $\mathrm{Y}_{\mathrm{i}}$ with respect to $\mathrm{Y}_{\mathrm{ii}}$ is decreased. While, bus 52 is the most insensitive bus based on $\mathrm{PI}_{1 \mathrm{Y}}$ and $\mathrm{PI}_{2 \mathrm{Y}}$, the admittance deviation of $Y_{i}$ with respect to $Y_{i i}$ is increased. From figure 7, buses 20 and 7 are the most sensitive buses based on $\mathrm{PI}_{V}$ and $\mathrm{PI}_{\mathrm{P}}$ respectively, because bus 20 has a maximum voltage deviation with respect to specified voltage. While, bus 7 is heavily loaded. On the contrary, buses from 2 to 8,26 and 25 are the most insensitive buses based on $\mathrm{PI}_{V}$, where these buses have a zero voltage deviation with respect to specified voltage. Based on $\mathrm{PI}_{\mathrm{P}}$, bus 8 is the most insensitive bus because this bus hasn't any load.

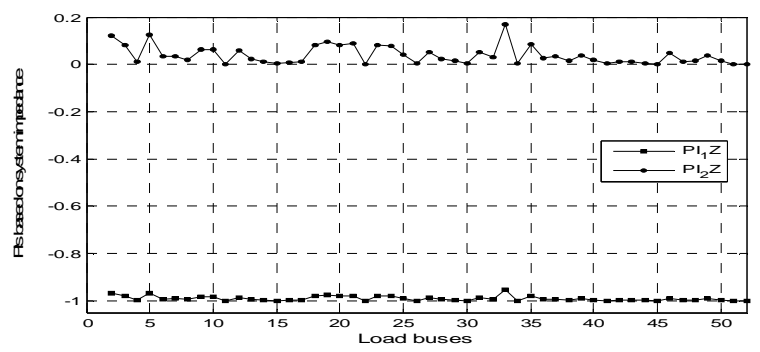

Fig. 5 PIs based on impedance matrix at normal condition for WDN system.

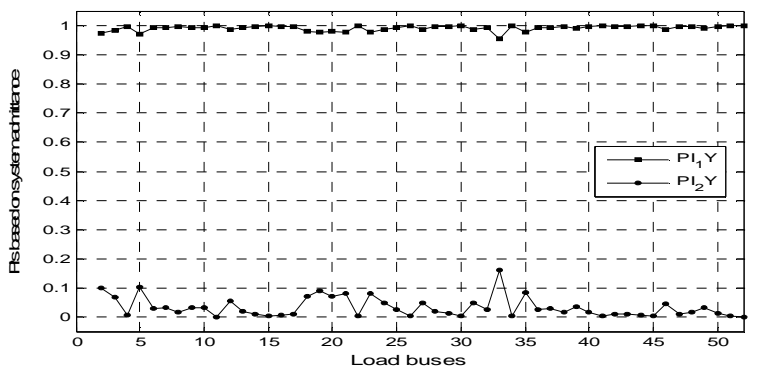

Fig. 6 PIs based on admittance matrix at normal condition for WDN system.

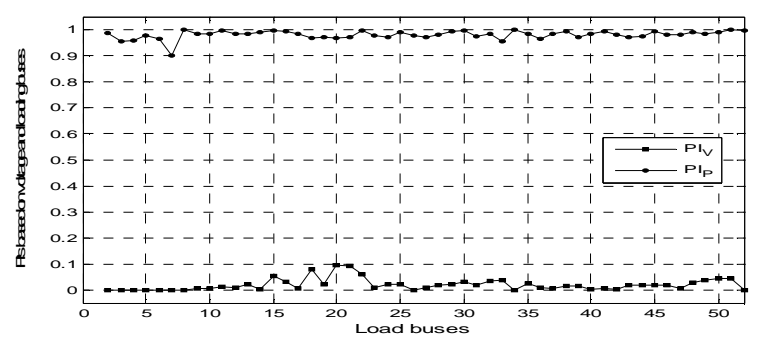

Fig. 7 PIs based on system load bus voltage and loading power indices at normal condition for WDN system.

\subsubsection{Emergency conditions}

\section{- Unexpected outage of transmission line}

Tables 3 and 4 show the proposed PIs of load-buses according to their severity due to the voltage collapse based on the system impedance, admittance matrices and voltage PIs for 14-bus test system. In these tables, it can be shown that, bus 3 is still the most sensitive bus based on system impedance and admittance PIs. On the contrary, bus 5 is still the most insensitive bus based on $\mathrm{PI}_{1 Z}$ and $\mathrm{PI}_{2 Z}$. While, bus 11 becomes the most insensitive based on $\mathrm{PI}_{1 \mathrm{Y}}$ and $\mathrm{PI}_{2 \mathrm{Y}}$. Based on $\mathrm{PI}_{\mathrm{V}}$, bus 8 is still the most 
sensitive bus. While, bus 4 becomes the most insensitive bus. In table III, the PIs, which based on system impedance, bus 4 is jumped towards to the sensitive bus. While, buses 9,8 , and 14 shifted one position towards the insensitive buses and the other buses are still in their list positions as in normal condition. Based on two PIs that based on system admittance, buses 2, 5 and 4 are shifted one and three positions towards the sensitive buses because these buses are connected to the two lines which are removed via bus 3 . While, buses $8,9,11,13$, and 14 are jumped one position towards the insensitive bus. In table IV, buses 2,12 , and 13 are jumped towards the sensitive buses. While, buses 9, 10, and 11 are jumped towards the insensitive buses.

Table 3 Ranking of load buses based on impedance and admittance matrices at lines outage for 14-bus system

\begin{tabular}{cccccccc}
\hline Rank & $\mathrm{PI}_{1 Z}$ & $\begin{array}{c}\text { Ran } \\
\mathrm{k}\end{array}$ & $\mathrm{PI}_{2 Z}$ & $\begin{array}{c}\text { Ran } \\
\mathrm{k}\end{array}$ & $\begin{array}{c}\mathrm{PI}_{1 Y} \\
\mathrm{Ran} \\
\mathrm{k}\end{array}$ & $\mathrm{PI}_{2 \mathrm{Y}}$ \\
\hline 3 & -0.640 & 3 & 0.778 & 3 & 0.829 & 3 & 0.499 \\
4 & -0.907 & 4 & 0.350 & 4 & 0.973 & 4 & 0.117 \\
9 & -0.915 & 9 & 0.321 & 8 & 0.974 & 14 & 0.102 \\
8 & -0.932 & 8 & 0.237 & 14 & 0.975 & 8 & 0.098 \\
14 & -0.941 & 14 & 0.229 & 9 & 0.988 & 9 & 0.054 \\
13 & -0.956 & 13 & 0.166 & 2 & 0.988 & 2 & 0.047 \\
10 & -0.969 & 10 & 0.129 & 13 & 0.989 & 13 & 0.042 \\
6 & -0.972 & 6 & 0.105 & 12 & 0.992 & 12 & 0.033 \\
12 & -0.977 & 12 & 0.089 & 10 & 0.994 & 10 & 0.027 \\
2 & -0.983 & 2 & 0.067 & 6 & 0.994 & 6 & 0.023 \\
11 & -0.988 & 11 & 0.050 & 5 & 0.995 & 5 & 0.023 \\
5 & -0.992 & 5 & 0.034 & 11 & 0.996 & 11 & 0.016 \\
\hline
\end{tabular}

Table 4 Ranking of load buses based on voltage PI at lines outage for 14-bus system

\begin{tabular}{cc}
\hline Rank & $\mathrm{PI}_{\mathrm{V}}$ \\
\hline 8 & 0.090 \\
6 & 0.070 \\
12 & 0.054 \\
13 & 0.045 \\
2 & 0.045 \\
11 & 0.043 \\
9 & 0.032 \\
10 & 0.029 \\
14 & 0.018 \\
5 & 0.013 \\
3 & 0.010 \\
4 & 0.001
\end{tabular}

Figures 8 - 10 show the proposed PIs of loadbuses according to their severity due to the voltage collapse for WDN system. In figure 8 , it is shown that, buses 33 and 52 are still the most sensitive and insensitive buses based on $\mathrm{PI}_{1 \mathrm{Z}}$ and $\mathrm{PI}_{2 \mathrm{Z}}$, respectively. Buses 5, 24, 25, 31 and 33 are jumped towards the sensitive buses, where the two lines that removed affect the buses $5,24,25,31$ which are connected with them. In figure 9, buses 33 and 52 are still the most sensitive and insensitive buses based on $\mathrm{PI}_{1 \mathrm{Y}}$ and $\mathrm{PI}_{2 \mathrm{Y}}$, respectively. While, buses 5, 24, 25 and 31 are also jumped towards the sensitive direction. In figure 10 , bus 20 is still the most sensitive bus based on $\mathrm{PI}_{\mathrm{V}}$. Also, buses from 2 to 8,26 and 25 are still the most insensitive buses based on $\mathrm{PI}_{\mathrm{V}}$. While, buses $11,13,24,28,29,30,31$, and 32 are jumped towards the sensitive buses, and the bus 25 is jumped towards the insensitive bus.

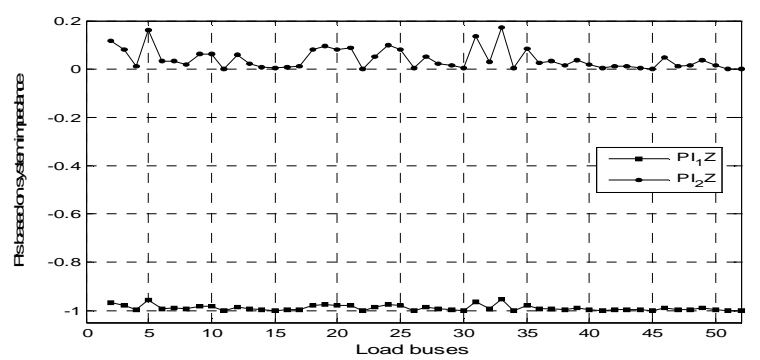

Fig. 8 PIs based on impedance matrix at line outage condition for WDN system.

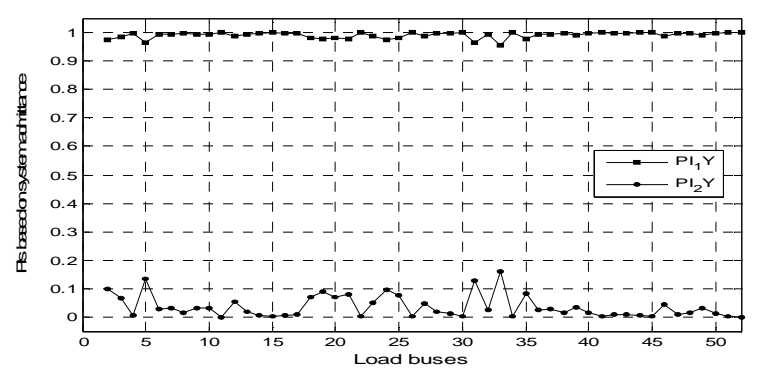

Fig. 9 PIs based on admittance matrix at line outage condition for WDN system.

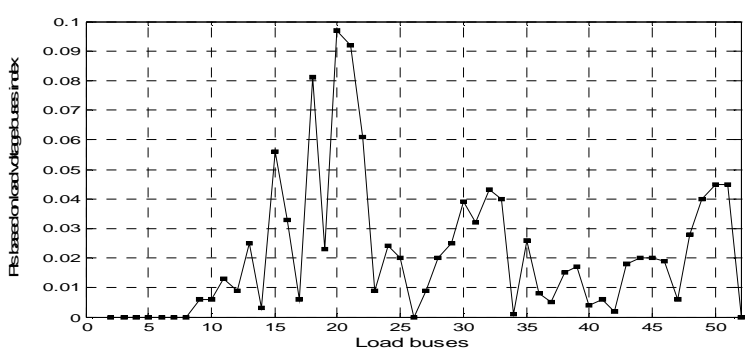

Fig. 10 PIs based on system load bus voltage index at line outage condition for WDN system.

\section{- Sudden increase in the load demand}

Tables 5 and 6 show the proposed PIs of loadbuses according to their severity due to the voltage collapse based on the system impedance, admittance 
matrices and voltage PIs for 14-bus test system. In these tables, it can be shown that, buses 3 and 5 are still the most sensitive and insensitive buses respectively, based on system impedance and admittance PIs as at normal condition. While, buses 8 and 3 are still the most sensitive and insensitive buses based on $\mathrm{PI}_{\mathrm{V}}$. In table $\mathrm{V}$, bus 14 is jumped towards the sensitive bus, due to the load increasing at this bus with $50 \%$. The two PIs based on the system impedance give the same ordering. Also, the two PIs based on the admittance give the same ordering.

Table 5 Ranking of load buses based on impedance and admittance matrices at load increasing for 14-bus system

\begin{tabular}{cccccccc}
\hline Rank & $\mathrm{PI}_{1 Z}$ & Rank & $\mathrm{PI}_{2 Z}$ & Rank & $\mathrm{PI}_{1 Y}$ & Rank & $\mathrm{PI}_{2 Y}$ \\
\hline 3 & -0.854 & 3 & 0.445 & 3 & 0.910 & 3 & 0.302 \\
14 & -0.918 & 14 & 0.283 & 14 & 0.964 & 14 & 0.136 \\
9 & -0.928 & 9 & 0.253 & 8 & 0.974 & 8 & 0.098 \\
8 & -0.941 & 8 & 0.211 & 9 & 0.988 & 9 & 0.048 \\
4 & -0.954 & 4 & 0.171 & 4 & 0.988 & 4 & 0.046 \\
13 & -0.957 & 13 & 0.159 & 13 & 0.989 & 13 & 0.042 \\
10 & -0.972 & 10 & 0.106 & 2 & 0.990 & 2 & 0.039 \\
6 & -0.973 & 6 & 0.103 & 12 & 0.992 & 12 & 0.033 \\
12 & -0.977 & 12 & 0.087 & 10 & 0.994 & 10 & 0.024 \\
2 & -0.983 & 2 & 0.065 & 6 & 0.994 & 6 & 0.023 \\
11 & -0.989 & 11 & 0.448 & 11 & 0.996 & 11 & 0.015 \\
5 & -0.993 & 5 & 0.027 & 5 & 0.998 & 5 & 0.008 \\
\hline
\end{tabular}

Table 6 Ranking of load buses based on voltage PI at load increasing for 14-bus system

\begin{tabular}{cc}
\hline Rank & $\mathrm{PI}_{\mathrm{V}}$ \\
\hline 8 & 0.090 \\
6 & 0.070 \\
11 & 0.056 \\
12 & 0.055 \\
9 & 0.054 \\
10 & 0.050 \\
13 & 0.048 \\
2 & 0.045 \\
14 & 0.028 \\
5 & 0.018 \\
4 & 0.016 \\
3 & 0.010
\end{tabular}

Figures 11-13 show the proposed PIs of loadbuses according to their severity due to the voltage collapse for the WDN system. In figure 11, it is shown that, buses 33 and 52 are still the most sensitive and insensitive buses based on $\mathrm{PI}_{1 \mathrm{Z}}$ and $\mathrm{PI}_{2 \mathrm{Z}}$, respectively. Bus 36 is jumped towards the sensitive bus, because of increasing the load at that bus by $50 \%$. In figure 12 , buses 33 and 52 are still the most sensitive and insensitive buses based on $\mathrm{PI}_{1 \mathrm{Y}}$ and $\mathrm{PI}_{2 \mathrm{Y}}$, respectively. Also, bus 36 is jumped towards the sensitive bus. In figure 13 , bus 20 is still the most sensitive bus based on $\mathrm{PI}_{\mathrm{V}}$. Also, buses from 2 to 8,26 and 25 are still the most insensitive buses.

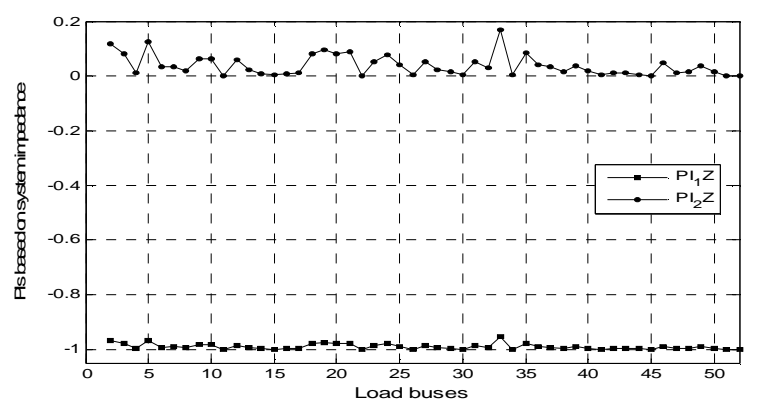

Fig. 11 PIs based on impedance matrix at load increasing condition for WDN system.

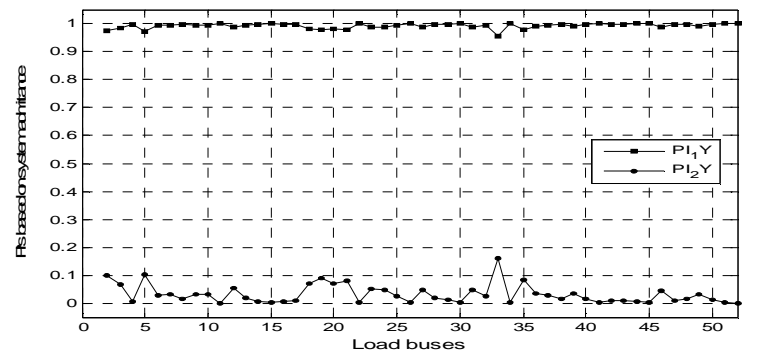

Fig. 12 PIs based on admittance matrix at load increasing condition for WDN system.

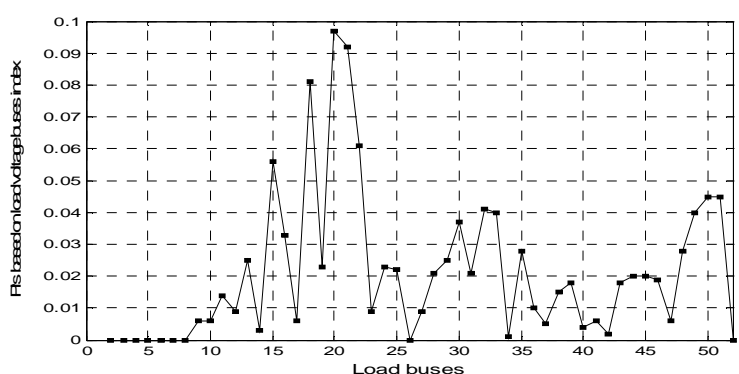

Fig. 13 PIs based on system load bus voltage index at load increasing condition for WDN system.

\section{CONCLUSION}

Different proposed of performance indices based on system impedance, admittance, voltage, and loading active power quantities under normal and emergency conditions have been efficiently presented. The results show that, the most sensitive and insensitive buses are the same or jumped one position at the normal and emergency conditions. This means that, the predicted most sensitive buses at the normal conditions are correctly picked. The four PIs based on impedance and admittance matrices give the same ordering of buses. The PIs based on 
load bus voltages and loading power, which measures the voltage deviation with respect to specified voltage and active power load deviation with respect to the total load power are efficiently applied. The advantages of the proposed performance indices are an efficient, simple, minimum time computation, noniterative process, and suitable for large scale systems.

\section{REFERENCES}

[1] I. Šmon, M. Pantoš, F. Gubina, " An improved voltage-collapse protection algorithm based on local phasors", Electric Power Systems Research, Vol. 78, No. 3, pp. 434-440, March 2008.

[2] I. Musirin and T. k. Abdul Rahman, "Estimating Maximum Loadability for Weak Bus Identification Using FVSI", IEEE Power Engineering Review, pp. 50-52, November 2002.

[3] K. Nithiyanathan, N. Manoharan, and V. Ramachandran, "An Efficient Algorithm for Contingency Ranking based on Reactive Compensation Index", Journal of Electrical Engineering, Vol. 57, No.2, pp.116-119, 2006.
[4] S. Sutha, and N. Kamaraj, "Real Power Contingency Ranking Using Wavelet Transform Based Artificial Neural Network (WNN)", International Journal of Electrical and Power Engineering 2 (2), pp. 116-121, 2008.

[5] H. Silveira, and A. Rocco, "Voltage Collapse Risk Associated to Under-Voltage Capacitive Compensation in Electric Power System Operation", American Journal of Applied Sciences 6 (4), pp.646-651, 2009.

[6] Jizhong Zhu, Kwoik Cheung, Davis Hwang and Ali Sadjadpour, "Operation Strategy for Improving Voltage Profile and Reducing System Loss", IEEE Trans. on Power Systems, Vol. 25, No. 1, pp. 390-397, January 2010.

[7] M. A. Pai, "Computer Techniques in Power System Analysis", McGraw-Hill, Inc. New York, 1979.

[8] R. A. El-Sehiemy, "Performance of Transmission Network Under Deregulated Electrical Power System", Ph. D. thesis, Minoufiya University, Faculty of Engineering, Egypt, August 2008. 